\title{
Correction to: Creation of Straight-Chain Cationic Polysaccharide-Based Bile Salt Sequestrants Made from Euglenoid $\beta$ - I,3-Glucan as Potential Antidiabetic Agents
}

Motonari Shibakami ' (D) Kazuhiko Shibata ${ }^{2}$ - Akira Akashi $^{3}$ • Nobuteru Onaka ${ }^{3} \cdot$ Jun Takezaki $^{3}$.

Gen Tsubouchi $^{3} \cdot$ Hiroaki Yoshikawa ${ }^{3}$

Published online: 2 January 2019

(C) Springer Science+Business Media, LLC, part of Springer Nature 2019

\section{Correction to: Pharm Res (2019) 36:23}

https://doi.org/10.1007/s I 1095-018-2553-8

The corresponding author (Motonari Shibakami) inadvertently failed to include his. ORCID ID: http://orcid.org/ 0000-0003-4484-2982

In the published article.

Publisher's note Springer Nature remains neutral with regard to jurisdictional claims in published maps and institutional affiliations.

The online version of the original article can be found at https://doi.org/l0. | 007/s | |095-0 | 8-2553-8

Motonari Shibakami

moto.shibakami@aist.go.jp

Biomedical Research Institute, National Institute of Advanced Industrial Science and Technology (AIST), Central 6th, I - I I Higashi, Tsukuba, Ibaraki 305-8566, Japan

2 Artisan Lab Co., Ltd. F3 Quartet I-24-3 Jiyugaoka, Meguro,

Tokyo I52-0035, Japan

3 Technical Research Center, KOBELCO Eco-Solutions Co., Ltd., I - I-4

Murotani, Kobe, Hyogo 65I-224I, Japan 